DEVELOPMENT OF A VORTEXING COMBUSTOR

(VC) FOR SPACE/WATER HEATING APPLICATIONS

(PROOF-OF-CONCEPT MODEL DEVELOPMENT)

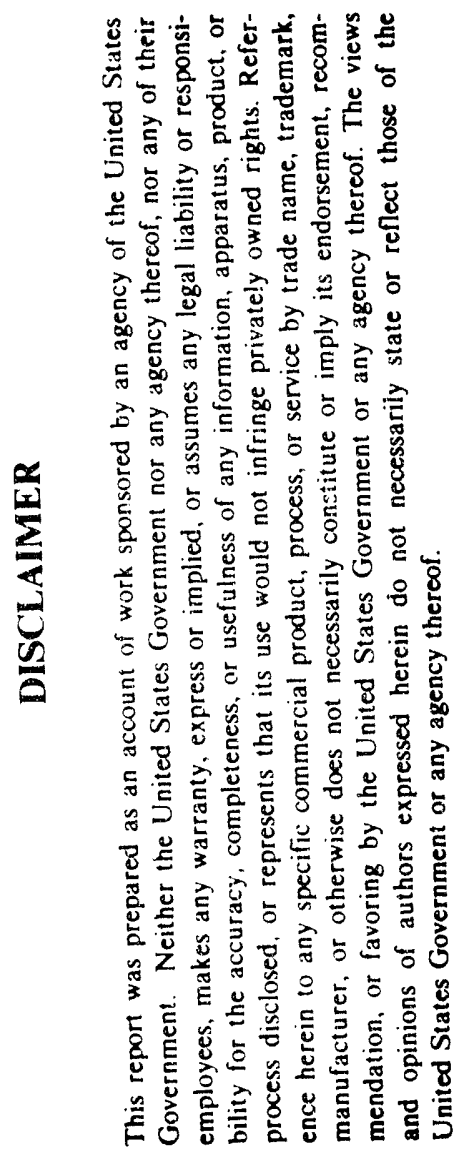

\author{
To \\ U.S. Department of Energy \\ Pittoburgh Energy Technology Center \\ TPO: John C. Winslow \\ (Phone) 412-675-6290 \\ P.O. Box 10940 \\ Pittaburgh, PA 15236 \\ for
}

Project No: DE-AI22-87PC79660

by

Tim r. Fu, Principal Inveetigator

Energy and Environment Department

Naval Civil Engineering Laboratory

Port Hueneme, CA 93043-5000

(Phone) 805-982-4675

September 1988

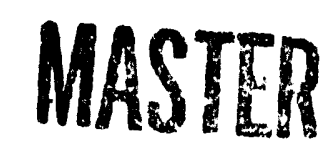

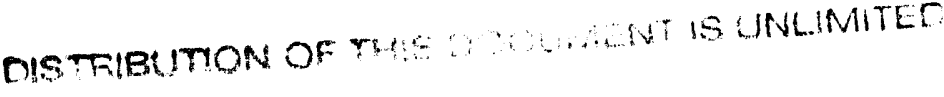


SUMMARY

This is the third quarterly technical progrese report for DE-AI2287 PC79660 covering the period between 1 May and 31 July 1988.

During this reporting period, the firing test of Dry Ultrafine Coal (DUC) in the $0.15 \mathrm{MB} / \mathrm{H}$ exploratory model has continued. Sufficient experience and insight have been accumulated to help finalize the design of the $0.6 \mathrm{MB} / \mathrm{H}$ experimental model. Pabrication of the $0.6 \mathrm{MB} / \mathrm{H}$ model is 338 complete. A Coal-Water Fued (CWF) loop for firing tests and an apparatus for testing CWF nozzle spray patterns are adso 33 complete. A new test facility which includes the flue gas cleaning facility (described in our first quarterly progress report) is operational. We are now able to conduct independent tesrs on both the 0.15 and $0.6 \mathrm{MB} / \mathrm{H}$ models without disruption to either model. Current efforta have been concentrated in permanently installing test apparatus/equipment in the new test facility area.

CWF tests in the $0.15 \mathrm{MB} / \mathrm{H}$ model and DUC teste in the $0.6 \mathrm{MB} / \mathrm{H} \mathrm{model}$ are expected to begin in september 1988 . 


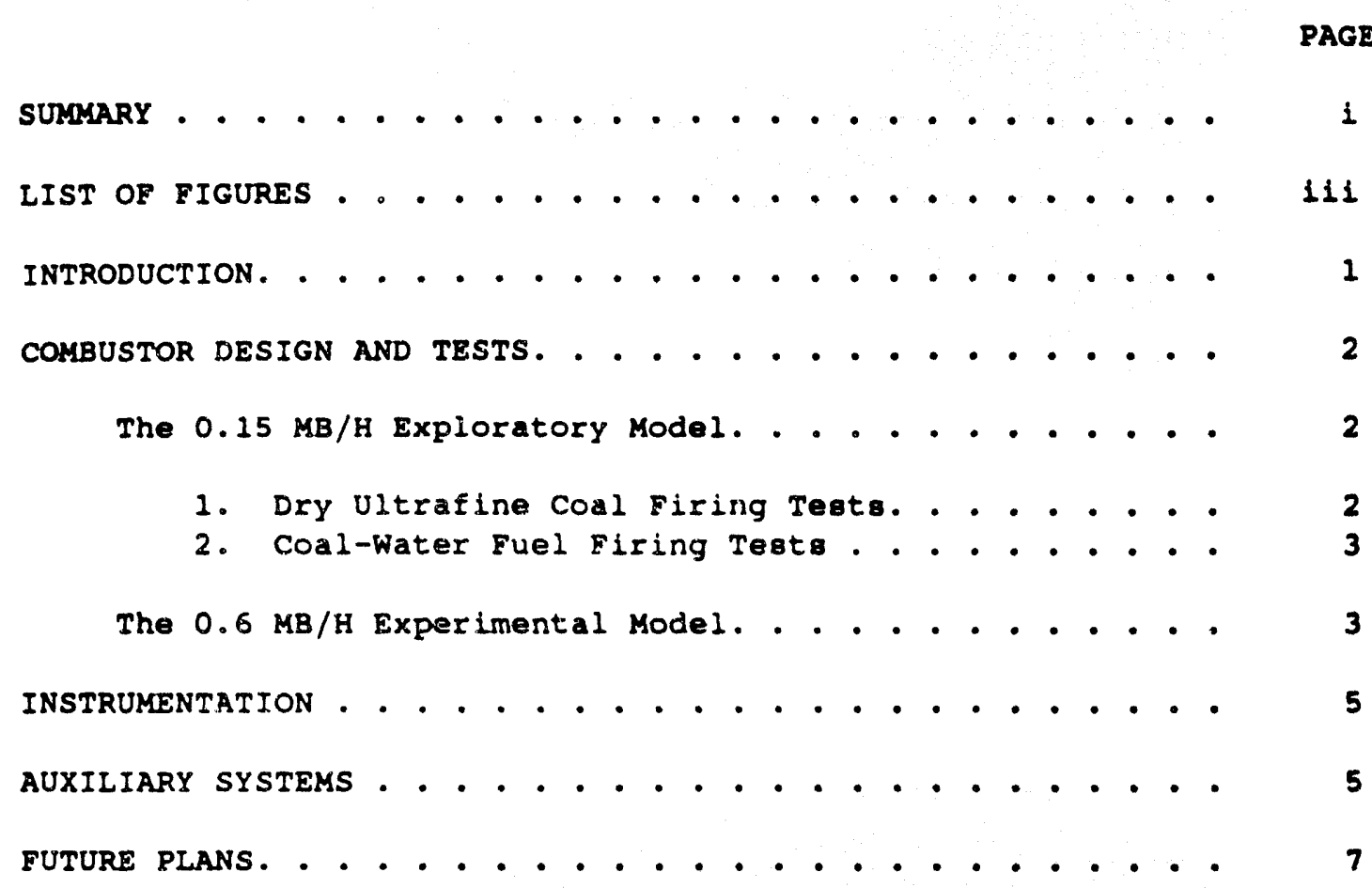




\section{LIST FIGURES}

PAGE

1. $0.6 \mathrm{MB} / \mathrm{H}$ experimental VC hot model. . . . . . . . . . 4

2. Preimninary flow diagram for vortex Combustor . . . . . . 6 experimental facility 
INTRODUUCTION

This is the third quarterly technical progregs report for the development of vortexing combustion technology under interagency agreement DE-AI22-87PC79660 covering the period between 1 May and 31 July 1988.

The overall effort for this development is described in our first quarterly technical progress report. In summary, it consiat of three major steps, the design, construction, and test of:

1. A $0.15 \mathrm{MB} / \mathrm{H}$ exploratory model,

2. $0.6 \mathrm{MB} / \mathrm{H}$ experimental model, and

3. A 2-4 MB/H proof-of-concept model.

During this reporting period, our efforts have been to conduct further dry ultrafine coal (DUC) firing teste using the $0.15 \mathrm{MB} / \mathrm{H}$ exploratory model, preparation for coal-water fuel (CWF) testg, ingcallation of test apparatus/equipment in our new test facility (a sheltered outdoor test area) just completed, and fabrication of the $0.6 \mathrm{MB} / \mathrm{H}$ experimental model. 
COMBUSTOR DESIGN AND TESTS

The $0.15 \mathrm{MB} / \mathrm{H}$ Exploratory Model

\section{Dry Ultrafine Coal Firing Tegts.}

Our experimental focus during this reporting period has been to: (1) determine the combustor'g primary to secondary air ratio; and (2) evaluate the merits of owirling vanes in the center tube. These efforte were directed towards raising $T_{2}$, the gao temperaturs in the water-cooled combustor annular space, to the desired $1650^{\circ} \mathrm{F}$ level. cold secondary air has the effect of lowering $T_{2}$ but it is counteracted by the increased combustion activity due to the fresh supply of oxygen. Results thus far shows that its net effect on $T_{2}$ is small and ambiguous.

Swirling vanes in the center tube cause the incompletely burned coal particles to fly toward the "hot" tube wall thereby accelerating the combustion process. This effect was observed from the resulting higher center tube gas temperature and higher estimated combustion efficiency (an increase from 0.77 to 0.83 ). Current efforts have succeeded in raising $T_{2}$ to as high as $1500^{\circ} \mathrm{F}$ but it is still below what is needed for efficient combustion.

Lower $T_{2}$ is due to the excessive cooling in the water-cooled section. Corrective measures and further experimentations have been planned for the next quarter. Among the several measures under consideration, one is to locate the water-cooled surfaces at the center tube. 


\section{Coal-Water Fuel Firing Tests.}

The required modifications to the adlabatic section of the combustor for CWF firing have been completed. A CWF loop for both firing and nozzle spray pattern teots is 33 installed. CWF firing tests will begin next quarter.

The $0.6 \mathrm{MB} / \mathrm{H}$ Experimental Model

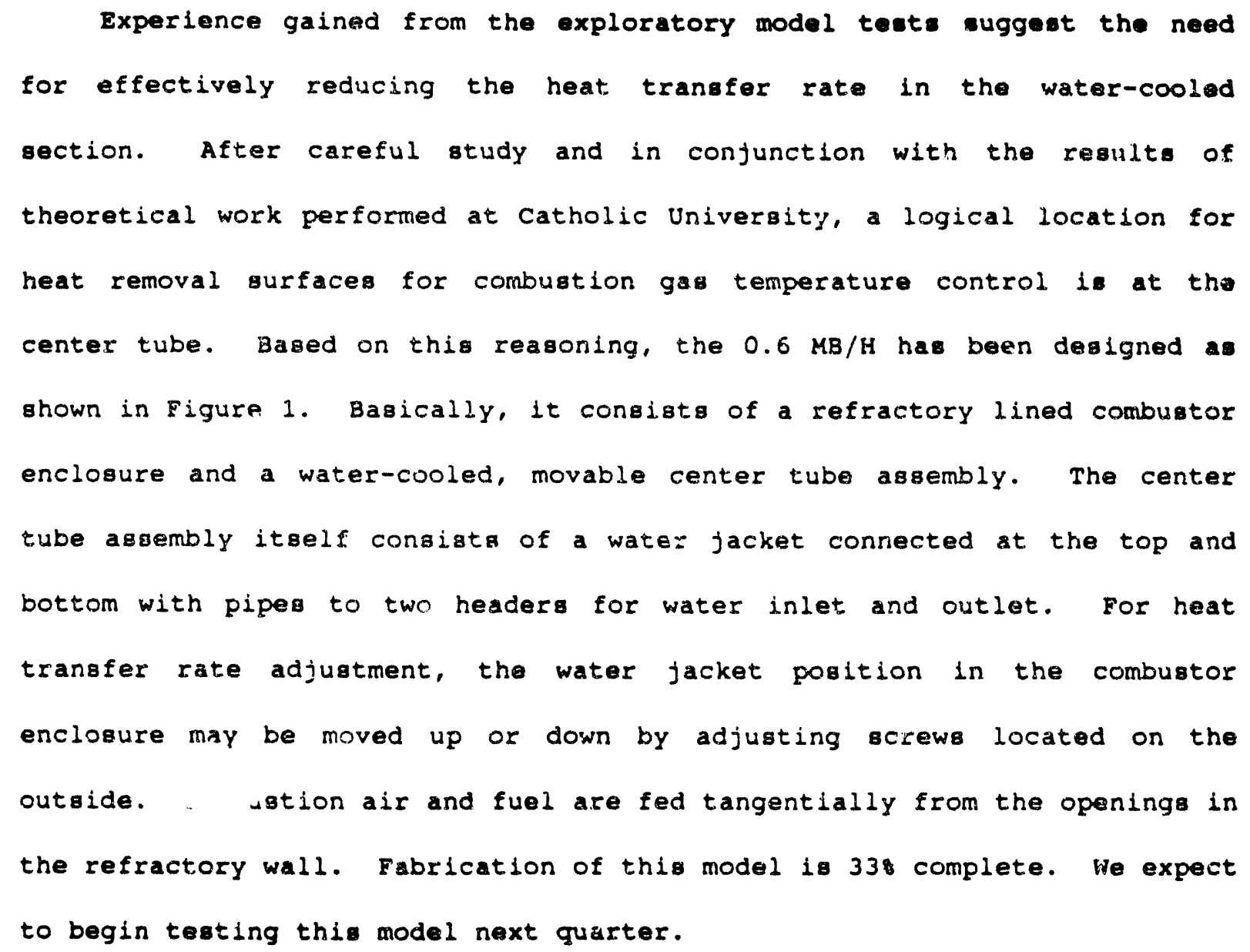




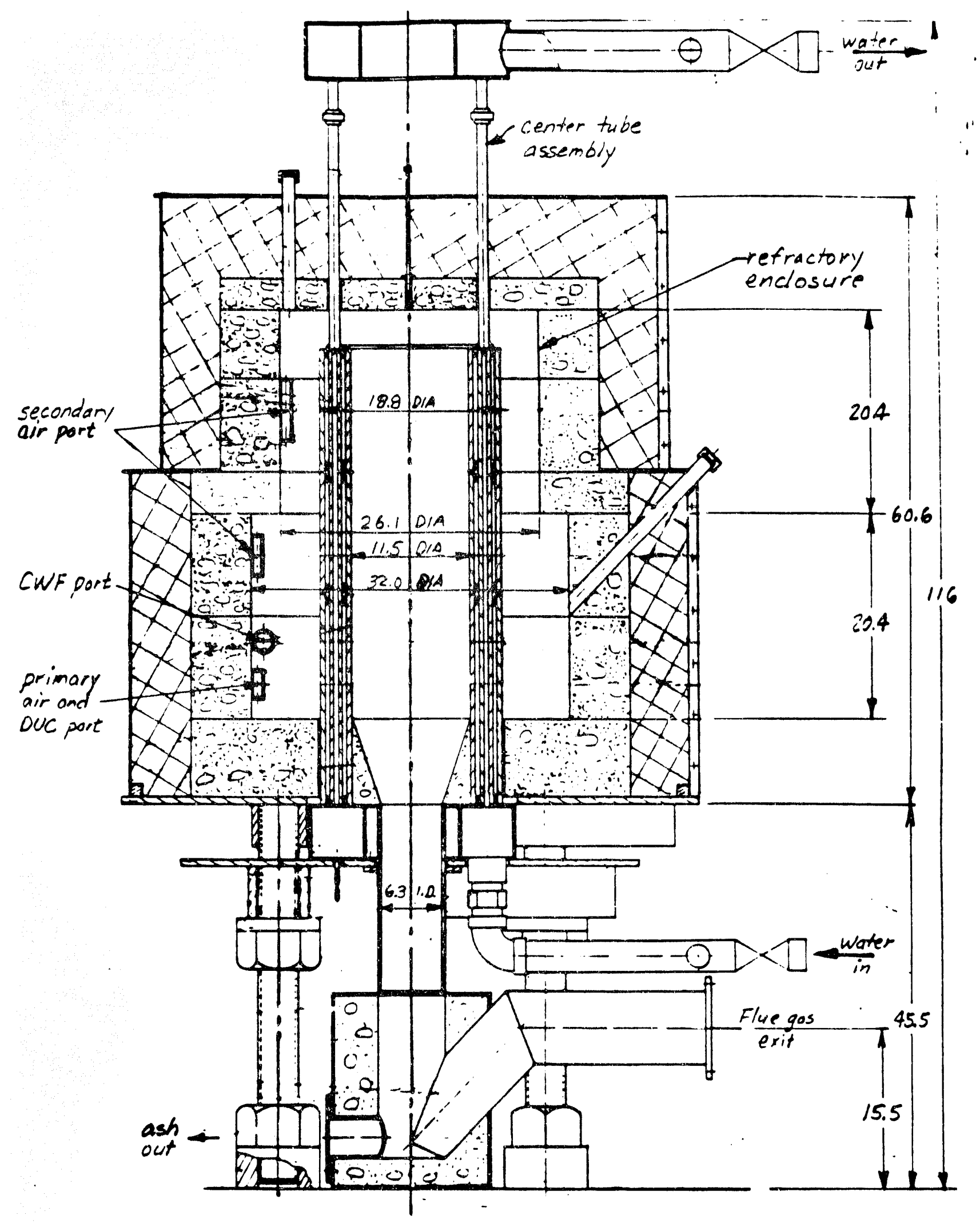

Figure 1. $0.6 \mathrm{MB} / \mathrm{H}$ experimental VC hot model. 


\section{INSTRUMENTATION}

The primary instrumentation for testing the proof-of-concept model is shown in Figure 2, the flow diagram of the overall experimental facility. A detailed list of items to be procured has been prepared and about 33 of the items are now on order. Instrumentation/ equipment procurement will be a continuing effort.

AUXILIARY SYSTEMS

An overall plan for testing the proof-of-concept model has been developed as shown in Figure 2. All components are sized based on the requirements for a $3 \mathrm{MB} / \mathrm{H}$ combustor output. With the exception of the Pulverized Coal (PC) feeding system and some sensors, all items are now on board. Equipment installation is planned to begin next fiscal year. Our current efforts focus on insuring the success of our subscale model tests and on the design of the proof-of-concept model.

A new test facility (a sheltered test area of approximately $26^{\prime} \times 60^{\prime}$ size) intended for conducting all subscale hot model tests is operational. Efforts have been concentrated on moving and permanently installing all test apparatug/equipment in this new test facility. The flue gar cleaning facility described in our firgt quarterly report is being calibrated. With all these operational, we will be able to test both the 0.15 and 0.6 MB/H models without disturbing each other. 


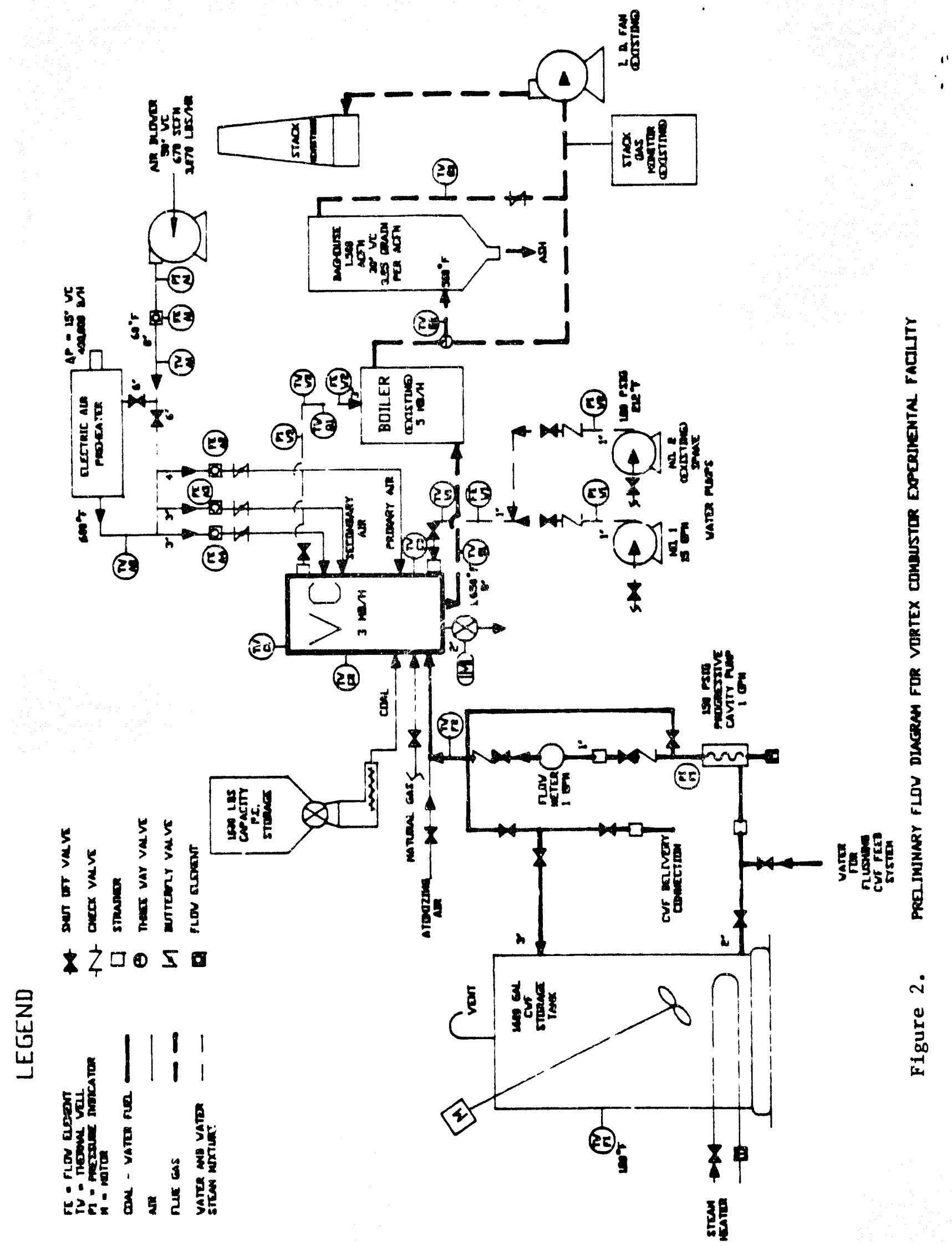


- Expand experimentation with the $0.15 \mathrm{MB} / \mathrm{H}$ model to fire CWF and to increase $\mathrm{T}_{2}$

- Complete calibration of the flue gas cleaning facility

- Conduct tegts on the $0.6 \mathrm{MB} / \mathrm{H}$ model

- Initiate detailed design of proof-of-concept model

- Install all test equipment in preparation for the proof-of-concept model tests.

- Invite sponsors and guest to visit our new test facility. 

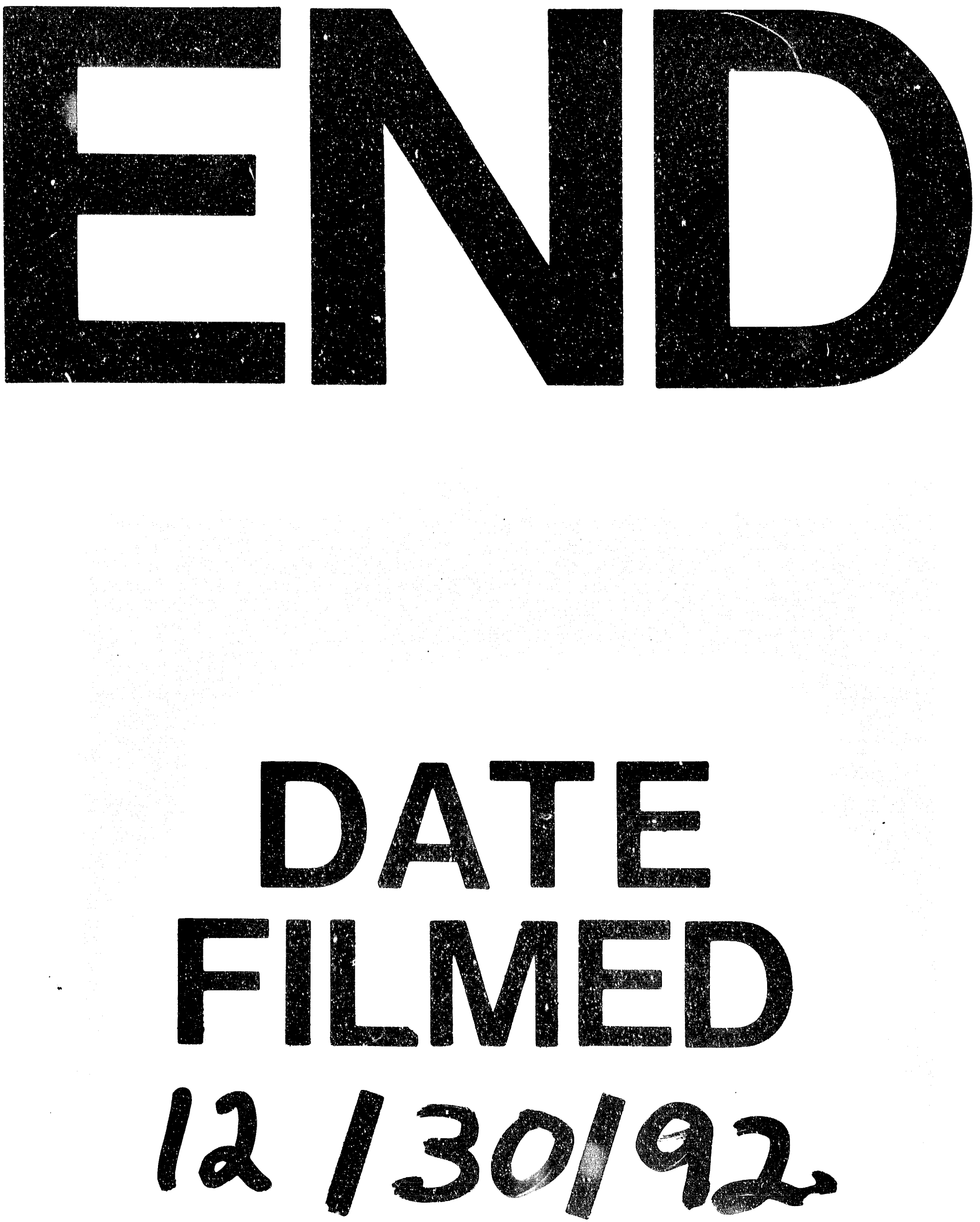


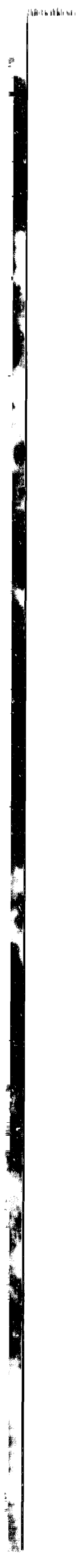

